\title{
Profile
}

\section{The International Foundation for Drug Efficacy and Safety}

\section{History}

During the early part of 1991 , it became clear that fundamental political changes were indeed to be carried through in what was at that time still the Union of Soviet Socialist Republics. A centralized economy which had existed for more than seventy years was rapidly giving way to a new form of society; the repercussions of those changes promised to be as drastic in the field of health as in any other. Where medicines were concerned there was both a challenge and an opportunity; the immediate challenge was to maintain for the moment sufficient of the existing system to ensure that needs would be met during a period of transition; the opportunity was to replace it with something not merely different but substantially better.

The USSR had since the revolution of 1917 become a largely industrialized society of more than 280 million people. In principle it was a society in which the pharmaceutical needs of the entire population were provided for, and indeed there was a system of importation, manufacture and distribution which kept the hospitals and pharmacies stocked. The reality was, however, that standards of quality and treatment were not fully up to date, and that the structure itself was now threatening to collapse as change came about. By the early months of 1991 in that industrialized society pharmaceutical manufacturing was accounting for no more than $20 \%$ of the supply of medicines needed by its citizens. In part that reflected the shortcomings of the old system, in part the demise of that system which had already set in. Production was low and declining further; trade with Eastern Europe had largely become paralyzed; some bulk chemical and pharmaceutical plants had already been closed for environmental reasons. As the Soviet Union gave way to the Commonwealth of Independent States, the problems were further aggravated; a dramatic decline in foreign currency reserves undermined essential imports, and home production stagnated as starting materials synthesized in one state of the Commonwealth ceased to be available to processing plants in others.

Although during the months that followed emergency help from many other nations did something to alleviate what could have been medical disaster, a more basic plan was needed to ensure the future of pharmaceutical supplies and medicinal therapy in the newly independent states of the C.I.S. Fortunately, preparations for such measures had been evolving during the long period of perestroika. On June 26th 1991, after more than 15 months of planning, the 
International Foundation for Drug Efficacy and Safety (IFDES) was formed in Moscow. With the ready support of both the Commission on Health Protection and Social Affairs of the Russian Federation Parliament and the Ministry of Health of the Russian Federation, the new non-profit Foundation set out to provide the basis for the future. Essentially it was designed to support the Russian Pharmacological Committee (which had taken over the functions of the former All-Union Committee as a drug authority, and was still de facto recognized in other C.I.S. countries), the State Center for Drug Expertise and the Ministry of Health, as they undertook a strategically developed set of initiatives and projects to provide pharmaceuticals to the Russian Federation itself and to collaborating member states in the C.I.S.

Founded by ten Russian medical scientists and two American scientists, the Foundation was first incorporated in Washington D.C. on September 5, 1991. It was subsequently registered in Basel, Switzerland, on October 10, 1991 and then under new legislation in Moscow on December 28, 1991. An internationally constituted Advisory Board to the Foundation was then established, drawn from the ranks of medical scientists, business executives, government officials and academia.

\section{Mission}

The Foundation has accepted a critical mission: To enhance health care in the Russian Federation and among the Commonwealth by increasing the quality and quantity of available drugs.

To fulfill this mission, the Foundation has identified a wide range of goals.

\section{Immediate goals}

To promote the supply of essential drugs from the international community to meet urgent needs during the current transition of the country's economy.

To assure the effective distribution of these drugs.

As these two goals are quickly addressed, work will begin on reaching the longer-term goals aimed at providing a permanent solution to the current crisis.

\section{Administration and regulation goals}

Refinement of the Russian drug regulation system and policy. This will include assistance to the Federation's efforts to develop a clear and concise system for assessing, approving, and registering pharmaceutical products for domestic use.

Integration of this system with similar regulatory programs throughout the world. As a result, pharmaceutical manufacturers will be able to meet uniform standards of 
high quality without unnecessary differences in regulations and administrative requirements.

Enhancing the capabilities and performance of the Russian Pharmacological Committee and the State Center for Drug Expertise. To do this, the Foundation will furnish advice and in-service training on organizational and management issues affecting pharmaceutical regulation and health administration.

\section{Education and information goals}

Development of international seminars and in-service training programs for Russian Federation medical and scientific personnel. To boost the available pool of knowledgeable personnel in this area, the Foundation will also help train Russian research specialists in the Federation, the United States, the European Community, Asia, and other countries. The Foundation will also arrange regular briefing visits for selected personnel to a wide range of foreign health agencies. Furthermore, it will organize international conferences and seminars on current and emerging laws, regulations, and rules related to health care and health care products in Russia and the collaborating Commonwealth states.

Broadly-based education programs for physicians. Additionally, the Foundation will seek to provide broadly-based education programs for physicians throughout the Federation on the appropriate use of new drugs prior to their introduction into the health care system.

\section{Goals for new facilities}

Establishment of Foundation laboratories and medical facilities. This will include the development and operation of internationally certified laboratories and clinical facilities, initially in Russia, to provide research testing capabilities in the Commonwealth that comply with both USFDA and EC guidelines, including USFDA Good Laboratory Practices, Good Clinical Practices, and Good Manufacturing Practices. These facilities will be operated on a not-for-profit basis available to the international and domestic communities.

\section{Goals for international market initiatives}

Assistance to Russian scientists, institutes, and entrepreneurs regarding the licensing of domestic pharmaceutical products outside the Federation.

Assistance to pharmaceutical manufacturers from outside Russia to help them effectively work within the Federation marketplace.

Provision of marketing-related information to international pharmaceutical companies through Foundation materials and activities. 


\section{Current activities}

Since its establishment, the Foundation has been successful in attracting the support and collaboration of a wide range of institutions including intergovernmental organizations, bilateral aid agencies, pharmaceutical corporations and national governmental bodies in the pharmaceutical field. Many have seen in the Foundation an opportunity to co-ordinate efforts to help the newly independent states of the former USSR, ensuring that aid is used as effectively as possible and that emergency help is progressively transformed into a lasting collaboration from which healthy new infrastructures can benefit. Initiatives currently in advanced stage of development include the establishment of a drug testing laboratory having both a controlling and an educational role, the training of clinical pharmacologists and assessors, the establishment of a modern drug regulatory system and the creation of fora in which Ministers of Health, experts, donors and industry can meet on equal terms.

\section{Information}

Information on the Foundation, its work and means of supporting its activities will gladly be made available from any of the Foundation's three offices:

IFDES, Suite 310, Administration Building, Starovolynskaya Street 10, Moscow 121358, Russian Federation. Tel. 7095-442-47-69.

IFDES, c/o AWI, Rathenaustrasse 12, D-3000 Hannover 1, Germany. Tel. (511) 368-1383; Fax (511) 324-130.

IFDES, c/o Philip Anderson \& Partners, 8381 Old Courthouse Road, Suite 140, Vienna, VA 22182, USA. Tel. (703) 442-0272; Fax (703) 790-1058. 